\section{A Budbreak-based Chilling and Heating Model for Predicting First Entry of Pecan Nut Casebearer}

\author{
Darrell Sparks ${ }^{1}$ \\ Department of Horticulture, University of Georgia, Athens, GA 30602
}

Additional index words. Carya illinoinensis, Acrobasis nuxvorella Neunzig, degree-days

\begin{abstract}
A modification of the chilling and heating model for pecan budbreak was used to describe the interactive effects of chilling and heating on the date of first entry of the pecan nut casebearer (PNC; Acrobasis nuxvorella Neunzig) into the pecan [Caryaillinoinensis (Wangenh.) K. Koch] fruit. Selected data from unpublished and published sources were used to construct the model. Base temperatures of 9.4 and $13.9 \mathrm{C}$ for chilling and heating, respectively, provided the best fit $\left(r^{2}=0.981\right)$ for the model used to predict PNC activity. An inverse relationship $\left[1 / Y=0.0037259\left(1-0.1 \mathrm{e}^{-0.0028069 x-574.9638969}\right)\right]$ was found between chilling (1 Dec. through February) and heating (beginning 1 Feb.) degree-days accumulated until entry of first-generation PNC into the pecan fruit. This model can be used to predict entry of first-generation PNC larvae into fruit over a range of geographic and climatic conditions and pecan genotypes. Model validation using 1994 data from two sites in Texas suggests precision is sufficient to use the model as a guide in managing nut casebearer control.
\end{abstract}

Pecan nut casebearer (PNC) feeds on developing pecan fruit. During a growing season, this insect can destroy a high percentage of fruit (Bilsing, 1926; Coppock, 1981; Hinrichs and Bieberdorf, 1953), resulting in reduced crop yields. This multivoltine insect can damage fruit from early growth until nut maturity (Bilsing, 1926). Controlling firstgeneration populations of PNC is essential for maximum nut yield and low-input agricultural practices. Spray applications for later generations not only increase costs and environmental damage but also may kill beneficial organisms (Mizell, 1991) that regulate other pecan pests, such as yellow pecan aphids [Monelliopsis pecanis Bissell and Monellia caryella (Fitch)].

The most effective insecticide application is targeted at first-generation larvae before they burrow into the fruit. Only 2 or 3 days may lapse between larvae hatching from the egg and entering into fruit (Bilsing, 1927). Sprays must be carefully timed because foliar insecticides are not effective once larvae enter the fruit, and systemic insecticides are unavailable. Several methods have been used to time control with insecticides. Timing has been based on predicting the development of certain PNC life stages, such as moth emergence (Bilsing, 1926; Calcote, 1983; Thomas and Hancock, 1968), egg laying (Hinrichs and Bieberdorf, 1953) or hatching (Nickels, 1938), or tree phenology [i.e., days after pollen shed-

\footnotetext{
Received for publication 8 June 1994. Accepted for publication 14 Nov. 1994. Appreciation is expressed to Gloria Belvan for technical assistance. The cost of publishing this paper was defrayed in part by the payment of page charges. Under postal regulations, this paper therefore must be hereby marked advertisement solely to indicate this fact.

${ }^{1}$ Professor of Horticulture.
}

ding (Pierce, 1946) or initial darkening of the stigmatic surfaces (Cochran, 1951; Hinrichs and Bieberdorf, 1953; Morrison et al., 1982)].

Insecticide application based on moth emergence (Bilsing, 1926) and egg laying (Hinrichs and Bieberdorf, 1953) has been and is used widely, although both procedures have been modified with time (Calcote, 1983; Coppock, 1981; Thomas and Hancock, 1968). However, a major problem exists with setting a spray date based on the number of days after a marker event, such as moth emergence. The problem is that continued development of the PNC depends on temperature (Ring and Harris, 1983), which may vary during the interval between the marker event and the date set for spray application. None of these spray guides account for the influence of temperature on insect development during this interval, although insecticide application based on egg laying is less risky.

Tree and insect phenology were combined into a single degree-day model (Ring and Harris, 1983) developed for College Station, Texas. This degree-day model, referred to as the Texas model, has a heating base of 3.3C. The starting date for heat accumulation at College Station is 12 Mar. The starting dates for other locations are determined by delaying the start day (12 Mar. ) by 1 day for each 2.72 days of difference between frost-free days at College Station and colder climates and accelerating by 1 day for the same interval between College Station and warmer climates (Ring et al., 1983). Alternatively, 10 days before $50 \%$ budbreak is sometimes used as the starting date (Aquirre and Harris, 1986; Reid et al., 1984). Regardless of when the model is initiated, heat is accumulated from a designated starting date until significant entry ( $2 \%$ of fruit clusters have evidence of larval feeding), at which time insecticides are applied. In practice, reliability of the Texas model is variable.
A starting date based on deviations in frostfree days from College Station assumes that environmental conditions preceding the starting date have no effect on insect development. Because a date based on frost-free days is fixed from year to year, the date may occur before or after budbreak, depending on whether spring is unseasonably early or late (Reid et al., 1984). The alternative starting date (10 days before $50 \%$ budbreak) requires an on-site inspection and the ability to estimate $50 \%$ budbreak. Budbreak becomes more staggered, and thus more difficult to estimate, within and among cultivars as accumulated chilling decreases (Sparks, 1993).

Despite the limitations of the Texas model, Ring and Harris (1983) clearly demonstrated that growth and development of all PNC life stages are a function of temperature, as suggested by previous researchers (Bilsing, 1926, 1927; Calcote, 1983; Gill, 1924; Reid, et al., 1984; Thomas and Hancock, 1968). PNC development is not only temperature dependent, but it also is synchronized with pecan phenology. Larval emergence from overwintering sites coincides with budbreak in pecan (Bilsing, 1926; Gill, 1924; Hinrichs and Bieberdorf, 1953; Ring et al., 1989; Thomas and Hancock, 1968), and initial entry into the fruit parallels pollination (Cochran, 1951; Hinrichs and Bieberdorf, 1953; Osburn et al., 1966; Pierce, 1946). The apparent synchronization of PNC development with pecan phenology suggests that any model to predict entry into the fruit might be improved by accommodating temperature effects on the time of budbreak and flowering.

Budbreak in pecan depends on the interactive effects of heating and chilling (Sparks, 1993). Because PNC activity begins with budbreak, the possibility also exists that this insect's development directly or indirectly depends on the interactive effects of heating and chilling. The Texas model (Ring and Harris, 1983) factored only one climatic influenceheating. The possible influence of winter chilling on insect activity was not considered. No single recommendation or model has proved reliable at all sites and across years for predicting the critical date for controlling firstgeneration PNC. My purpose was to develop a heating and chilling model for predicting the first entry of the PNC into the pecan fruit as a guide for timing controls against this insect.

\section{Materials and Methods}

In this study, first-generation larvae were targeted as the stage in the PNC life cycle to develop a model because of their critical role in determining subsequent fruit damage (Gill, 1924; Grando and Marek, 1976; Hinrichs and Bieberdorf, 1953; Reid et al., 1984; Thomas and Hancock, 1968). The date considered critical to establishing a model for insecticide control was the day when $\approx 1 \%$ or fewer fruit clusters showed entry of PNC larvae. The rationale was not to use this date for spray application but as a guide to initiate a scouting program to assess egg laying and hatching, which in turn would be the index for spraying. 
Selected published and unpublished data on the date of the first entry into the fruit by first-generation larvae were used (Table 1). Studies reporting observations made fewer than three times weekly or in an insectary were not used. Daily observations were made in all but one study (i.e., Reid et al., 1984), in which case the date of first entry was estimated from plots of infestation counts vs. time.

Daily maximum and minimum temperatures were obtained from the National Oceanic and Atmospheric Administration station nearest the pecan orchards for which PNC activity was reported in each study (Table 1). Chilling and heating are expressed as degreedays. One degree-day was accumulated for each degree that the daily mean ambient temperature was below or above a given base. The mean was the average of the maximum and minimum for the day. The degree-day was referred to as a chilling degree-day if the daily average was below the base; it was referred to as a heating degree-day if it was above the base. Chilling degree-days were accumulated from 1 Dec. through February and heating degree-days from $1 \mathrm{Feb}$. to date of larvae first entry into the fruit as reported for a particular study. Accumulation dates are the same as those used for predicting pecan budbreak (Sparks, 1993), except heating was accumulated to date of first entry rather than average budbreak date. Similar accumulation dates were used because of the apparent synchronization of the PNC with pecan phenology. As demonstrated in the pecan budbreak model, heating degree-days with daily minima $<2.2 \mathrm{C}$ are inefficient because predictability decreases. Thus, they were not included in heat accumulation. Heating degree-days with daily minima $<2.2 \mathrm{C}$ were rare.

Selecting the appropriate temperature bases used in the model to determine first entry of PNC into the fruit involved a sequence of calculations. First, accumulated heating and chilling over a range of temperatures were determined. Calculation for accumulation of chilling degree-days was from 2.8 to $11.7 \mathrm{C}$ and heating degree-days was from 12.8 to $21 \mathrm{C}$, using increments of $0.55 \mathrm{C}$ in both cases. The interval 2.8 to $11.7 \mathrm{C}$ included the most efficient chilling base for budbreak (3.9C) (Sparks, 1993), and the interval 12.8 to 21C included the most efficient heating base (18.3C) for tree development to about pistillate anthesis (Sparks, 1989). Next, the heating and chilling $\times$ first entry interaction was calculated for all possible combinations of heating and chilling degree-days accumulated. The combination producing the highest $r^{2}$ was selected as the predictive equation. The equation used to evaluate these combinations was the inverse of a Mitscherlich's modified growth equation: $1 / \mathrm{Y}=\beta\left[1-\mathrm{pe}^{-\alpha\left(\mathrm{x}-\mathrm{x}_{\mathrm{p}}\right)}\right]$ (Ware et al., 1982), where $1 / \mathrm{Y}=$ heat accumulated from $1 \mathrm{Feb}$. until first entry, $X=$ chill accumulation, $\beta=$ the upper asymptotic value that $\mathrm{Y}$ approaches for large values of $X, \alpha=$ parameter associated with rate of change, $X_{p}=$ the value of $X$ where $Y$ approaches $(1-p) \beta$; e = exponential function, $\mathrm{p}=$ fractional value $<1$ that designates where the estimated value of $\mathrm{X}_{\mathrm{p}}$ is determined.
Mitscherlich's equation was selected to model PNC activity because entry of the first generation is a growth index of this insect. For all equations, the $r^{2}$ values were calculated as 1.0 - residual sum of squares : corrected total sum of squares ratio (SAS Institute, 1985). Because $\mathrm{Y}$ is a large number, $1 / \mathrm{Y}$ was expressed to eight decimal places.

The chill-heat model was validated using 1994 data for Eagle Pass and Crystal City, Texas. Predictions with the chill-heat model were compared with predictions made with the Texas model. Differences in observed minus predicted dates for the models were the basis for comparison.

\section{Results and Discussion}

The best fit $\left(r^{2}=0.981\right)$ for the chill-heat model used to describe PNC activity was obtained with base temperatures of $9.4 \mathrm{C}$ for chilling and $13.9 \mathrm{C}$ for heating. The curve derived using these base temperatures demonstrated an inverse relationship between chilling (1 Dec. through February) and heating (beginning at 1 Feb.) degree-days accumu- lated until entry of first-generation PNC into the pecan fruit (Fig. 1). The inverse relationship is as found for the chilling and heating model for pecan budbreak (Sparks, 1993). Implications are similar to those for budbreak. That is, as the chilling degree-days increase, the heating degree-days required until initial entry of first-generation PNC decrease. Also similar to the budbreak model, PNC will develop without chilling once sufficient heat accumulates.

Goodness of fit of the chill-heat model is high (Table 2), despite the many variables in the data sets used to develop the model. First entry was reported by various investigators over many years. Furthermore, the observations were made over a wide geographic range, representing extremely diverse growing conditions and cultivars. The net result is that the model may be widely applicable.

Applying the model is further supported by equation validation. Observed date minus predicted date for Crystal City and Eagle Pass in 1994 was -2 and -3 days, respectively. The predicted dates are within the error range (Table 2 ) of the model. In contrast, the observed date

Table 1. First entry source of pecan nut casebearer data by locations, years, and references.

\begin{tabular}{lll}
\hline \hline Location $^{2}$ & \multicolumn{1}{c}{ Years } & \multicolumn{1}{c}{ Source } \\
\hline Crystal City, Texas & $1988-91 ; 1993$ & D. Sparks, unpublished data \\
Eagle Pass, Texas & 1993 & D. Sparks, unpublished data \\
College Station, Texas & $1980-81$ & Ring and Harris, 1983 \\
Chetopa, Kan. & $1982-83$ & Reid et al., 1984 \\
Carlsbad, N.M. & 1975 & Grando and Marek, 1976
\end{tabular}

${ }^{2}$ Temperature data were taken from indicated location, except Chetopa, Kan., in which case temperature data were from Columbus, Kan.

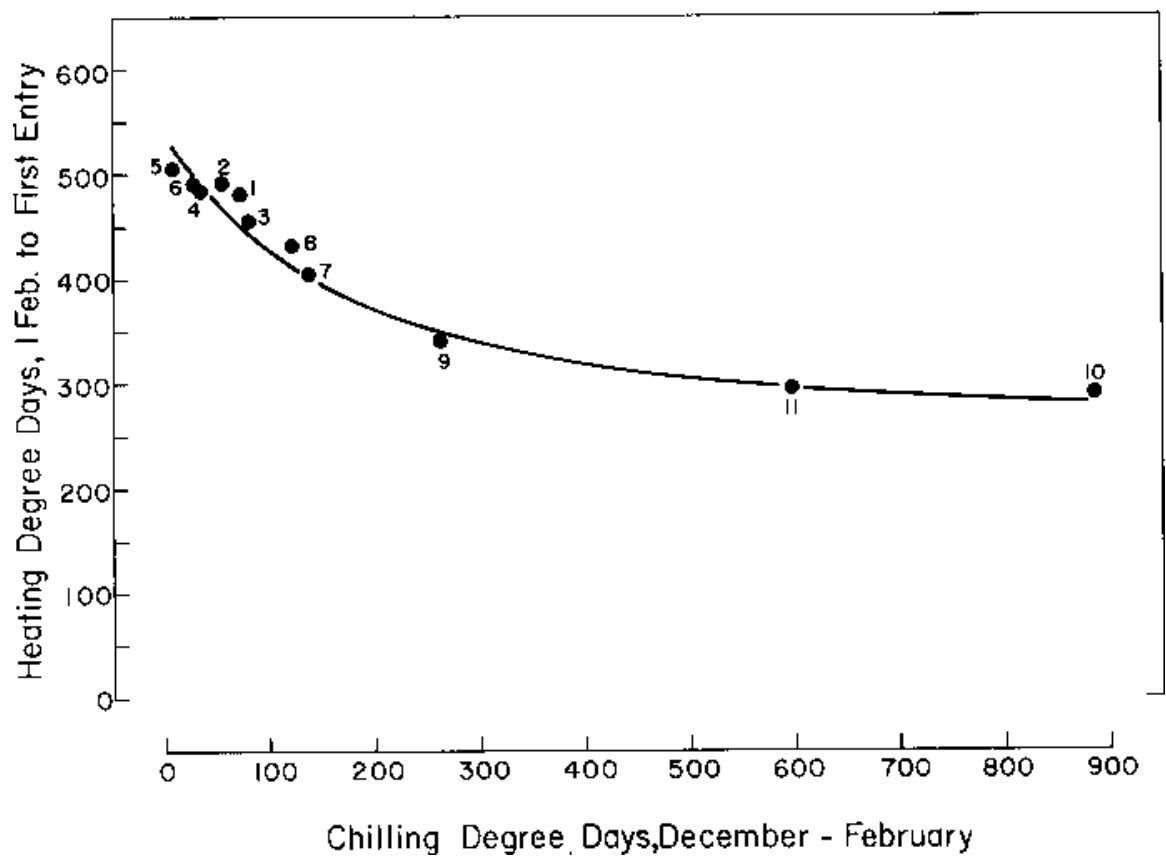

Fig. 1. Relationship between heat accumulation from 1 Feb. to first entry of the pecan nut casebearer and chill accumulation in December, January, and February. Heating degree-days were calculated from base 13.9C and chilling degree-days from 9.4C. The relationship is described by $1 / \mathrm{Y}=0.0037259[1-$ $\left.0.1 \mathrm{e}^{-0.0028069(x-574.9638969)}\right], r^{2}=0.981$. Coefficient of determination is significantly different from zero at $P \leq 0.01$. Numbers within the figure designate location and year: 1 to $5=$ Crystal City, Texas (1988-91, 1993); 6 = Eagle Pass, Texas (1993); 7 and $8=$ College Station, Texas (1980 and 1981); $9=$ Carlsbad, N.M. (1975); 10 and $11=$ Chetopa, Kan. (1982 and 1983). 

was -10 days for Crystal City and -6 days for Eagle Pass. These predictions are within the error range of the model (Table 2), but the error is much greater than in the chill-heat model. In addition to being more accurate, the chill-heat model is easier to use than the Texas model because neither an on-site estimate of budbreak nor a calculation of starting date relative to College Station is required.

Precision of the chill-heat model is sufficient to allow the equation to be tried as a guide in managing PNC control in pecans under diverse growing conditions. Growers interested in killing the insect before the first entry should begin scouting for eggs once $60 \%$ of the heat required for initial entry of the PNC into the pecan fruit has accumulated. Scouting from the time of $60 \%$ heat accumulation will allow at least 6 days before initial entry. Insecticide application then could be timed for 4 to 5 days following initial egg laying (Hinrichs and Bieberdorf, 1953), which would closely coincide with initial egg hatch (Bilsing, 1926). Likewise, growers who prefer to spray at the time of first entry into the fruit should begin scouting before the predicted date. Early scouting will minimize the possibility of error in the model as well as error in thermograph calibration.

The basic assumption of the model developed in this study is that initial entry of PNC into the fruit is determined by an interactive temperature regime. Another pecan insect, hickory shuckworm [Cydia caryana (Fitch)], has an apparent chilling response as demonstrated by the inverse relationship between the length of diapausing larvae chilling to initia- minus the predicted date for the Texas model

tion of moth emergence (Gunasena and Harris, 1987). The actual biological mechanism controlling PNC may be biotic rather than abiotic factors. A possible trigger for a particular stage in insect development could be a stimulus released by the pecan tree. Thus, the influence of chilling and heating predicted by the model would be directly on the tree (causing budbreak) and indirectly on PNC. If so, its activity would depend totally on heat accumulation from time of budbreak; thus, heating degree-days from budbreak to initial entry of the PNC would be a constant, as assumed in the Texas model (Aquirre and Harris, 1986; Reid et al., 1984). Regardless of the mechanism that controls the activity of PNC, the current model can be used to determine the time to begin control procedures.

\section{Literature Cited}

Aquirre, L.A. and M.K. Harris. 1986. Predicting biological events of the pecan nut casebearer using a degree-day model in Coahuila, Mexico. Southwestern Entomol. 11:263-267.

Bilsing, S.W. 1926. The life history and control of the pecan nut casebearer (Acrobasis caryae). Texas Agr. Expt. Sta. Bul. 328

Bilsing, S.W. 1927. Studies on the biology of the pecan nut casebearer (Acrobasis caryae). Texas Agr. Expt. Sta. Bul. 347.

Calcote, V.R. 1983. Pecan nut casebearer: Use of blacklight traps and other methods for determining management practices. Misc. Publ. Entomol. Soc. Amer. 13:63-76.

Cochran, J.H. 1951. Control of the pecan nut casebearer with organic insecticides. Proc. Southeastern Pecan Growers Assn. 44:72-73.

Coppock, S. 1981. Pecan nut casebearer control by aerial application. Proc. Okla. Pecan Growers Assn. 51:31-43.

Table 2. Accuracy of the predicted date of first entry of the nut casebearer using the chill-heat and the Texas model.

\begin{tabular}{|c|c|c|c|c|c|c|}
\hline \multirow[b]{2}{*}{ Location } & \multirow[b]{2}{*}{ Year } & \multirow[b]{2}{*}{$\begin{array}{c}\text { Observed } \\
\text { date }\end{array}$} & \multicolumn{2}{|c|}{ Predicted (date) } & \multicolumn{2}{|c|}{ Observed - predicted } \\
\hline & & & $\begin{array}{l}\text { Chill-heat } \\
\text { model }\end{array}$ & $\begin{array}{l}\text { Texas }^{2} \\
\text { model }\end{array}$ & $\begin{array}{c}\text { Chill-heat } \\
\text { model }\end{array}$ & $\begin{array}{l}\text { Texas } \\
\text { model }\end{array}$ \\
\hline \multirow[t]{5}{*}{ Crystal City, Texas } & 1988 & 26 Apr. & 25 Apr. & 4 May & 1 & -8 \\
\hline & 1989 & 25 Apr. & 24 Apr. & 1 May & 1 & -6 \\
\hline & 1990 & 24 Apr. & 24 Apr. & 6 May & 0 & -12 \\
\hline & 1991 & 22 Apr. & 23 Apr. & 1 May & -1 & -9 \\
\hline & 1993 & 1 May & 4 May & 5 May & -3 & -4 \\
\hline Eagle Pass, Texas & 1993 & 3 May & 4 May & 1 May & -1 & 2 \\
\hline \multirow[t]{2}{*}{ College Station, Texas } & 1980 & 22 May & 22 May & 18 May & 0 & 4 \\
\hline & 1981 & 10 May & 10 May & 10 May & 0 & 0 \\
\hline Carlsbad, N.M. & 1975 & 5 June & 6 June & 2 June & -1 & 3 \\
\hline \multirow[t]{2}{*}{ Chetopa, Kan. } & 1982 & 12 June & 12 June & 19 June & 0 & -7 \\
\hline & 1983 & 22 June & 22 June & 24 June & 0 & -2 \\
\hline $\mathrm{SEE}^{y}$ & & & & & \pm 1.0 & \pm 5.0 \\
\hline
\end{tabular}

${ }^{2}$ Starting date for heat accumulation based on deviations in frost-free days from College Station, Texas (Ring et al., 1983).

${ }^{\mathrm{y}} \mathrm{SEE}=\mathrm{SE}$ of estimate (days).
Gill, J.B. 1924. Important pecan insects and their control. U.S. Dept. of Agr. Farmer's Bul. 1364.

Grando, R. and R. Marek. 1976. Pecan nut casebearer control program for Eddy and Chaves counties. Proc. Western Pecan Conf. 10:13.

Gunasena, G.H. and M.K. Harris. 1987. Effect of humidity and cold storage on diapause termination of hickory shuckworm larvae. Southwestern Entomol. 12:25-31.

Hinrichs, H.A. and G.A. Bieberdorf. 1953. The pecan nut casebearer and its control. Oklahoma Agr. Expt. Sta. Bul. B-392.

Mizell, R.M. 1991. Pesticides and beneficial insects: Application of current knowledge and future needs, p. 47-54. In: B.W. Wood and J.A. Payne (eds.). Pecan husbandry: Challenges and opportunities. U.S. Dept. of Agr., Agr. Res. Serv., Southeastern Fruit and Tree Nut Res. Lab., Byron, Ga.

Morrison, F., W. Reid, and F. Crowe. 1982. Pecan pest control. Kansas State Coop. Ext. Serv. Bul. MF-230.

Nickels, C.B. 1938. The timing of spray applications for the control of the pecan nut casebearer. U.S. Bur. Entomol. and Plant Quarantine. E422.

Osburn, M.R., W.C. Pierce, A.M. Phillips, J.R. Cole, and G.E. Kenknight. 1966. Controlling insects and diseases of the pecan. U.S. Dept. Agr. Hdbk. 240.

Pierce, W.C. 1946. Timing spray applications to control the pecan nut casebearer. J. Econ. Entomol. 39:76-78.

Reid, W., R.L. Dinkins, and M.K. Harris. 1984. Predicting the development of the pecan nut casebearer. Southwestern Entomol. 9:421-426.

Ring, D.R., V.R. Calcote, and M.K. Harris. 1983. Verification and generalization of a degree-day model predicting pecan nut casebearer (Lepidoptera: Pyralidae) activity. Environ. Entomol. 12:487-489.

Ring, D.R. and M.K. Harris. 1983. Predicting pecan nut casebearer (Lepidoptera: Pyralidae) activity at College Station, Texas. Environ. Entomol. 12:482-486.

Ring, D.R., M.K. Harris, and J.A. Payne. 1989. Sequential sampling plan for integrated pest management of pecan nut casebearer (Lepidoptera: Pyralidae). J. Econ. Entomol. 82:907909.

SAS Institute. 1985. SAS user's guide: Statistics, Version 5 ed. SAS Institute, Cary, N.C.

Sparks, D. 1989. Predicting nut maturity of the pecan from heat units. HortScience 24:454455.

Sparks, D. 1993. Chilling and heating model for pecan budbreak. J. Amer. Soc. Hort. Sci. 118:2935.

Thomas, J.G. and B.G. Hancock. 1968. Tree banding.... Sensitive timing method for nut casebearer sprays. Pecan Quart. 2(1):4-7.

Ware, G.O., K. Ohki, and L.C. Moon. 1982. The Mitscherlich plant growth model for determining critical nutrient deficiency levels. Agron. J. 74:88-91. 